\title{
PENGARUH TERAPI FAMILY PSYCHOEDUCATION (FPE) TERHADAP KECEMASAN DAN BEBAN KELUARGA DALAM MERAWAT ANGGOTA KELUARGA DENGAN SKIZOFRENIA DI KECAMATAN BOLA KABUPATEN SIKKA, NUSA TENGGARA TIMUR
}

\author{
Adelheid R. Herminsih, Wisnu Barlianto, Rinik Eko Kapti \\ Program Studi Magister Keperawatan Fakultas Kedokteran Universitas Brawijaya \\ Jl. Veteran Malang Jawa Timur \\ E-mail: adelheid643@gmail.com
}

\begin{abstract}
Schizophrenia is a disease process that affects perceptions, emotions, social behavior and the ability to accept reality correctly. Families with schizophrenics often feel anxiety and burdens associated with client care. The problem can be solved by giving FPE therapy. This study aims to explain the effect of Family Psychoeducation (FPE) therapy on anxiety and family burden in caring for family members with schizophrenia. This research uses quasi experiment research pre-post test with control group. The number of respondents in this study were 18 respondents for the control group and 18 respondents for the treatment group. The study was conducted in District Bola from 24 May to 28 June 2017. Giving therapy done by the researchers themselves who have obtained a license from nurse specializing in mental health nursing. Data analysis used in this research is dependent $t$ test and independent $t$ test. The result of dependent $t$ test of anxiety and load test was obtained significance value $<0,05$, this result showed significant decrease of anxiety and load after FPE therapy. While the results of independent $t$ test showed that the significance of anxiety and family burden $<0.05$ which means that there is a significant difference in reducing anxiety and family burden between the treatment and control group after being given FPE therapy, that is, with an average decrease in anxiety and burden For the treatment and control groups of 10.11 and 3.5, respectively. This means that FPE is more effective in reducing family anxiety. Thus it is expected that FPE can be applied as an alternative therapy in reducing the anxiety of families who care for people with schizophrenia.
\end{abstract}

Keywords : family psychoeducation, anxiety, family burden

\begin{abstract}
Abstrak : Skizofrenia merupakan proses penyakit yang mempengaruhi persepsi, emosi, perilaku sosial dan kemampuan menerima realita dengan benar. Keluarga dengan penderita skizofrenia seringkali merasakan kecemasan dan beban yang berkaitan dengan perawatan klien. Masalah tersebut dapat diatasi dengan pemberian terapi FPE. Penlitian ini bertujuan menjelaskan pengaruh terapi Family Psychoeducation (FPE) terhadap kecemasan dan beban keluarga dalam merawat anggota keluarga dengan skizofrenia. Penelitian ini menggunakan desain penelitian quasi experiment pre-post test with control group. Jumlah responden dalam penelitian ini 18 responden untuk kelompok kontrol dan 18 responden untuk kelompok perlakuan. Penelitian dilakukan di Kecamatan Bola mulai tanggal 24 Mei-28 Juni 2017. Pemberian terapi dilakukan oleh peneliti sendiri yang telah mendapatkan lisensi dari perawat spesialis jiwa. Analisis data yang digunakan dalam penelitian ini adalah dependent $t$ test dan independen $t$ test. Hasil analisis dependent $t$ test kecemasan dan beban didapatkan nilai signifikansi< 0,05 , hasil ini menunjukkan penurunan kecemasan dan beban secara bermakna setelah diberikan terapi FPE. Sedangkan hasil analisis independent $t$ test menunjukkan bahwa nilai signifikansi kecemasan dan beban keluarga $<0,05$ yang berarti bahwa ada perbedaan yang bermakna dalam menurunkan kecemasan dan beban kelurga antara kelompok perlakuan dan kontrol setelah diberikan terapi FPE, yaitu dengan rata-rata penurunan kecemasan dan beban untuk kelompok perlakuan dan kontrol masing-masing yakni 10,11 dan 3,5. Hal ini berarti bahwa FPE lebih efektif dalam menurunkan kecemasan keluarga. Dengan demikian diharapkan bahwa FPE bisa diaplikasikan sebagai alternative terapi dalam menurunkan kecemasan keluarga yang merawat penderita skizofrenia.
\end{abstract}

Kata Kunci : family psychoeducation, kecemasan, beban keluarga.

\section{PENDAHULUAN}

Skizofrenia merupakan suatu sindrom klinis atau proses penyakit yang mempengaruhi persepsi, emosi, perilaku sosial dan kemampuan menerima realita dengan benar (Videbeck, 2008; Cerino, S., et.al., 2011). Data Riskesdas 2013, ditemukan bahwa prevalensi gangguan jiwa berat (termasuk skizofrenia) mencapai 1,7 per mil atau 1-2 orang dari 1.000 warga di Indonesia. Prevalensi gangguan jiwa berat 
di Nusa Tenggara Timur NTT) mencapai 1,6 per mil (1-2 orang dari 1000 penduduk).

Gejala utama skizofrenia berupa gangguan proses pikir, dimana pembicaraan sulit dimengerti, isi pikir yang tidak sesuai realita (delusi atau waham), disertai gangguan persepsi panca indera yaitu halusinasi, dan disertai tingkah laku yang aneh, seperti berbicara atau tertawa sendiri (APA, 2013; Birindelli, N., et.al., 2014). Penderita skizofrenia membutuhkan treatment untuk mengubah perilaku tersebut yang bukan hanya dilakukan di rumah sakit atau puskesmas tetapi dapat dilakukan oleh keluarga di rumah (Chan, Yip, Tso, Cheng, \& Tam, 2009; Johnson, 2012).

Beberapa penelitian menunjukkan bahwa keluarga pasien adalah sumber utama dukungan dan pengasuhan untuk pasien psikiatri serta merupakan kelompok pemberi pelayanan terbesar karena sebagian besar pasien tinggal dan dirawat oleh keluarganya sendiri (Maldonado, J.G., Urı'zar, A.C., 2007; Tel, Sarac, Günaydin, Medik, \& Dogan, 2010; APA, 2013; Stuart, 2013). Keluarga merupakan support system yang bisa diberdayakan karena keluarga merupakan bagian penting individu yang tidak dapat dipisahkan. Keluarga harus bersifat stabil dan mampu bertahan dalam setiap kondisi dengan harapan mampu menyelesaikan masalah yang ada (Friedman, 2010). Dukungan dari keluarga akan memberikan keberhasilan keluarga dalam merawat dan mengasuh penderita skizofrenia.

Merawat penderita skizofrenia menimbulkan banyak permasalahan bagi keluarga. Penelitian sebelumnya menunjukkan bahwa keluarga mungkin mengalami disfungsional yang digambarkan sebagai gangguan psikologis selama merawat anggota keluarga dengan skizofrenia (Mitsonis, et al., 2012; Rodrigo, Fernando, Rajapakse, De Silva, \& Hanwella, 2013; Shah, Sultan, Faisal, \& Irfan, 2013), tidak hanya menurunkan kualitas hidup mereka sendiri (Quah, 2014) namun berpengaruh juga dalam kualitas perawatan (Fleming, et al., 2006). Gangguan psikologis yang diderita antara lain stres, frustrasi, kurangnya interaksi sosial, menurunnya harga diri, depresi dan kecemasan (Cabral, L., Duartea, J., Ferreiraa, M., Santos, C., 2014). Sebanyak
$66 \%$ dari pengasuh memiliki gejala kecemasan dalam merawat anggota keluarga yang mengalami gangguan jiwa (Vazquez,et al., 2013).

Keluarga penderita skizofrenia juga mengalami beban yang sangat besar, yang memiliki efek negatif pada semua bidang kehidupan (Devaramane, 2011). Adanya anggapan bahwa bila memiliki anggota keluarga yang menderita gangguan jiwa adalah aib bagi keluarga juga menjadi beban subyektif keluarga (Ingkiriwang, 2010; WonPat-Borja, Yang, Link, \& Phelan, 2012). Jika beban keluarga tinggi maka akan mempengaruhi perawatan penderita gangguan jiwa karena keluarga adalah caregivers utama yang akan meningkatkan risiko kekambuhan dan menyebabkan prognosis yang lebih buruk (Sadock and Sadock, 2010).

Studi pendahuluan yang dilakukan pada 8 keluarga pasien, $5(62 \%)$ keluarga mengatakan merasa was-was, cemas dan khawatir melhat kondisi pasien. Keluarga juga mengatakan kadang-kadang merasa tidak tenang jika berada dekat pasien. Terkadang keluarga mengeluh sulit tidur dan memilih untuk menghindari kontak dengan pasien dan hanya kontak pada waktu tertentu saja. Mereka juga merasa trauma dan terbebani atas tindakan kekerasan yang dilakukan oleh pasien dan takut kalau kejadian itu terulang lagi. Beberapa keluarga juga mengatakan bahwa sakit yang dialami oleh anggota keluarga merupakan sakit akibat guna-guna atau santet sehingga keluarga tidak membawa ke sarana pelayanan kesehatan apalagi sampai saat ini propinsi Nusa Tenggara Timur (NTT) belum memiliki rumah sakit jiwa.

Pandangan masyarakat Bola secara umum menganggap bahwa bila salah seorang anggota keluarga menderita skizofrenia merupakan aib bagi penderita dan keluarganya. Gangguan ini masih menghasilkan kesalahpahaman, prasangka, kebingungan,dan ketakutan. Selain itu, gangguan jiwa juga dianggap penyakit yang disebabkan oleh hal-hal supranatural. Hal yang dialami oleh keluarga dan masyarakat Bola merupakan ungkapan kecemasan dan beban keluarga yang dirasakan selama merawat penderita skizofrenia. Kecemasan dan beban keluarga ini dapat diatasi dengan mengembangkan metode 
pemecahan masalah yang efektif (Maldonado, J.G., Urı'zar, A.C., 2007). yaitu dengan terapi keluarga atau lebih dikenal dengan Family Psychoeducation (FPE) (National Institute for Health and Clinical Excellence, 2014). FPE dapat memberikan pemahaman yang mendalam tentang kondisi gangguan jiwa yang dialami sehingga pasien maupun keluarganya merasa lebih terkontrol dan kecemasannya menurun (Yadev dan Kar, 2014). Selain itu, FPE juga dapat mengembangkan dan meningkatkan kemampuan keluarga dalam merawat penderita dan mengatasi masalah kesehatan jiwa dalam keluarga, mempercepat penyembuhan dan kemungkinan kambuh dapat dicegah (Pahlavanzadeh et al, 2010). Penelitian Gonzales (2010) menemukan bahwa FPE efektif menurunkan beban keluarga dalam merawat anggota keluarga yang menderita gangguan jiwa atau pshycosis. Terapi FPE juga mampu menangani masalah psikososial yang dialami oleh keluarga dalam merawat penderita skizofrenia yang sudah mendapatkan perawatan dan pengobatan (Maldonado, J.G. \& Uri'zar, A.C., 2007). Berdasarkan uraian diatas, diketahui bahwa FPE efektif mengatasi masalah psikososial keluarga dalam merawat anggota keluarga dengan penyakit fisik maupun mental seperti skizofrenia yang sudah pernah mendapatkan perawatan dan pengobatan di sarana kesehatan. Namun, di beberapa daerah tertentu masih banyak penderita skizofrenia yang belum mendapatkan pengobatan sehingga peneliti tertarik untuk meneliti lebih dalam mengenai pengaruh terapi FPE terhadap kecemasan dan beban keluarga dalam merawat penderita skizofrenia.

\section{METODE}

Desain penelitian ini adalah "quasi experimental pre-post test with control group" dengan intervensi psikoedukasi keluarga. Penelitian dilakukan untuk mengetahui perubahan kecemasan dan beban keluarga dalam merawat anggota keluarga dengan skizofrenia sebelum dan sesudah diberikan perlakuan berupa terapi FPE. Pada penelitian ini membandingkan perbedaan kecemasan dan beban keluarga pada dua kelompok keluarga yang merawat anggota keluarga dengan skizofrenia di Kecamatan Bola yaitu kelompok perlakuan yang mendapat terapi FPE serta pada kelompok kontrol yang hanya mendapatkan pendidikan kesehatan/health education saja tanpa FPE. Populasi dalam penelitian ini adalah seluruh keluarga yang mempunyai anggota keluarga yang menderita skizofrenia di Kecamatan Bola. Sampling yang digunakan yaitu purposive sampling. Berdasarkan pendataan ditemukan 99 penderita skizofrenia. Besar sampel minimal pada penelitian dapat dihitung dengan rumus penelitian eksperimen menurut Supranto (2010), sehingga diperoleh besar sampel sebanyak 36 orang.

Kriteria inklusi penelitian antara lain : 1) Ibu penderita skizofrenia yang tinggal serumah dengan penderita skizofrenia yang belum pernah mendapatkan pengobatan di pelayanan kesehatan, 2) lbu dengan penderita skizofrenia yang belum berkeluarga, 3) Ibu penderita skizofrenia yang sudah merawat penderita $>1$ tahun, 4) ibu penderita skizofrenia yang bekerja sebagai ibu rumah tangga dengan tingkat pendidikan SD - SMP, 5) ibu penderita skizofrenia dengan penghasilan keluarga < Rp 2.500.000.,/bulan, 6) ibu penderita skizofrenia yang berusia < 60 tahun, 7) ibu penderita skizofrenia yang bukan single parent, 8) bersedia menjadi responden dalam penelitian dan dibuktikan dengan penandatanganan dalam lembar persetujuan responden, 9) bisa membaca dan menulis.

Instrumen yang digunakan kuesioner kecemasan dan beban. Hasil uji validitas yang dilakukan pada 10 responden didapatkan hasil seluruh item pertanyaan dalam kuesioner kecemasan dan beban dinyatakan valid dengan $r$ hasil $>r$ tabel $(0,632)$. Hasil ini menunjukkan bahwa kedua instrumen tersebut valid. Uji reliabilitas pada kuesioner kecemasan didapatkan nilai crobach's coefficient-alpha 0,961 dan kuesioner beban 0,968, nilai ini lebih besar dari nilai r-tabel sehingga dinyatakan reliable. Penelitian dilaksanakan pada bulan Mei-Juni 2017.

\section{HASIL PENELITIAN}

\section{Karakteristik dasar responden penelitian}

Berdasarkan penelitian maka diperoleh hasil sebagai berikut : Karakteristik responden diperoleh rata-rata usia 
responden kelompok perlakuan adalah 57,44 dan kelompok kontrol adalah 55,39. Pendidikan dengan proporsi terbesar berada pada jenjang pendidikan SMP baik pada kelompok kontrol yaitu sebanyak 13 responden $(77,22 \%)$ maupun kelompok perlakuan sebanyak 10 responden $(55,56 \%)$. Penghasilan keluarga antara kelompok kontrol dan kelompok perlakuan hampir sama yakni <1.500.000,-. Pada kelompok perlakuan sebanyak 17 responden $(94,44 \%)$ dan kelompok kontrol sebanyak 16 (88,89\%). Sebagian besar responden sudah merawat penderita skizofrenia selama 6-10 tahun. Pada kelompok kontrol, sebanyak 10 responden $(55,56 \%)$ dan kelompok perlakuan sebanyak 11 responden $(61,11 \%)$.

Hasil uji homogenitas dari karakteristik usia, pendidikan, penghasilan keluarga serta lama merawat penderita skizofrenia. Nilai $\mathrm{p}$ yang didapatkan untuk karakteristik usia adalah 0,065 , pendidikan
$=0,637$, penghasilan keluarga $p=1,000$ dan lama merawat penderita adalah 0,127. Hasil uji homogenisitas masing-masing karateristik responden memiliki nilai $p>$ 0,05 yang berarti bahwa karakteristik responden pada kelompok perlakuan dan kelompok kontrol adalah sama atau tidak ada beda.

\section{Hasil Uji Normalitas Data}

Hasil Uji Normalitas Data menunjukkan bahwa nilai kecemasan dan beban keluarga memiliki distribusi data yang normal, hal ini dibuktikan dengan hasil $p$-value pada semua data (Kecemasan keluarga sebelum dan sesudah penkes pada kelompok control, Beban keluarga sebelum dan sesudah penkes pada kelompok kontrol, Kecemasan keluarga sebelum dan sesudah terapi FPE pada kelompok perlakuan, Beban keluarga sebelum dan sesudah terapi FPE pada kelompok perlakuan) memiliki nilai diatas $0,05(p>0,05)$.

\section{Analisis Bivariat}

Tabel 1. Perbandingan Rerata Skor Kecemasan dan Beban Keluarga Sebelum dan Sesudah Terapi FPE

\begin{tabular}{|c|c|c|c|c|}
\hline \multirow{2}{*}{ Kelompok } & \multicolumn{2}{|c|}{ Kecemasan } & \multicolumn{2}{|c|}{ Beban } \\
\hline & Perlakuan & Kontrol & Perlakuan & Kontrol \\
\hline Sebelum & $47,78 \pm 2,10$ & $47,89 \pm 4,54$ & $48,50 \pm 3,18$ & $46,56 \pm 3,78$ \\
\hline Sesudah & $37,06 \pm 2,55$ & $47,22 \pm 4,39$ & $41,72 \pm 2,70$ & $45,22 \pm 3,11$ \\
\hline$p$-value & 0,000 & 0,144 & 0,000 & 0,072 \\
\hline
\end{tabular}

Hasil analisis pada tabel 3 menunjukkan bahwa pada kelompok perlakuan terjadi perubahan rata-rata nilai kecemasan sebelum dan sesudah test baik pada kelompok perlakuan dan pada kelompok kontrol. Pada kelompok perlakuan rata-rata nilai kecemasan sebelum dilakukan terapi FPE adalah 47,78 sedangkan setelah terapi FPE diperoleh nilai 37,06 . Penurunan rata-rata nilai kecemasan kelompok perlakuan bermakna secara statistik $(p=0,000)$ dimana nilai $p$ value lebih kecil dari nilai alpha $(\alpha=0,05)$ $(p=0,000<\alpha=0,05)$.

Pada kelompok kontrol juga terjadi perubahan rata-rata nilai kecemasan sebelum (pre test) dan sesudah (post test). Sebelum diberikan penyuluhan kesehatan, rata-rata kecemasan 47,89 dan sesudah penyuluhan kesehatan nilai rata-rata kecemasan menurun menjadi 47,22. Perubahan rata-rata nilai kecemasan pada kelompok kontrol secara statistik tidak bermakna, dimana nilai $p$ sebesar 0,144 berada diatas nilai alpha $(\alpha=0,05)$ sehingga dapat disimpulkan bahwa pemberian penyuluhan kesehatan tidak berpengaruh terhadap kecemasan.

Rata-rata nilai beban sebelum terapi

FPE sebesar 48, 50 sedangkan sesudah dilakukan terapi FPE adalah 41,72. Penurunan rata-rata nilai beban ini bermakna secara statistik, dimana nilai $p$ value $(p=0,000)$ lebih kecil dari nilai alpha $(p=0,000<\alpha ; 0.05)$. menunjukkan bahwa terdapat perbedaan yang signifikan nilai beban pada kelompok perlakuan sebelum dan sesudah pemberian terapi FPE. Hal ini berarti bahwa pemberian terapi FPE pada kelompok perlakuan berpengaruh 
menurunkan beban keluarga dalam merawat anggota keluarga dengan skizofrenia. Secara statistik, penurunan rata-rata nilai beban pada kelompok kontrol Tidak bermakna, dimana nilai $p$ sebesar 0,072 berada diatas nilai alpha $(\alpha=0,05)$ sehingga dapat disimpulkan bahwa pemberian penyuluhan kesehatan tidak berpengaruh terhadap beban keluarga dalam merawat anggota keluarga dengan skizofrenia.

Tabel 2. Perbandingan Kecemasan Dan Beban Keluarga

\begin{tabular}{|c|c|c|c|}
\hline Variabel & Perlakuan & Kontrol & Selisih \\
\hline Skor Kecemasan (post) & $37,06 \pm 2,55$ & $47,22 \pm 4,39$ & 10,11 \\
\hline Skor Beban (post) & $41,72 \pm 2,70$ & $45,22 \pm 3,11$ & 3,5 \\
\hline
\end{tabular}

Hasil analisis tabel 2. menunjukkan bahwa nilai kecemasan keluarga pada kelompok perlakuan setelah pemberian terapi FPE lebih rendah sebesar 10,11 dibandingkan dengan nilai kecemasan kelompok control dengan nilai $p$ kecemasan sebesar $0,000(p<\alpha)$, sehingga dapat disimpulkan bahwa secara statistik terdapat perbedaan yang signifikan kecemasan keluarga antara kelompok kontrol dan kelompok perlakuan setelah diberikan intervensi. Sedangkan pada variabel beban, nilai beban keluarga kelompok perlakuan setelah pemberian terapi FPE lebih rendah sebesar 3,5 dibandingkan dengan nilai beban kelompok kontrol. Secara statistik diperoleh nilai $p$ sebesar 0,001 $(p<\alpha)$, sehingga dapat disimpulkan bahwa terdapat perbedaan yang signifikan beban keluarga antara kelompok kontrol dan kelompok perlakuan sesudah diberikan intervensi.

\section{PEMBAHASAN}

\section{Perbedaan Kecemasan Keluarga Dalam Merawat Anggota keluarga dengan Skizofrenia Sebelum dan Sesudah Terapi FPE}

Hasil penelitian menunjukkan bahwa nilai rata-rata kecemasan pada kelompok perlakuan sebelum terapi FPE sebesar 47,78 dan setelah terapi FPE sebesar 37,06 . Perbedaan rata-rata nilai kecemasan sebelum dan setelah terapi FPE cukup bermakna. Fakta lain yang mendukung bahwa terapi FPE berpengaruh terhadap kecemasan keluarga dalam merawat anggota keluarga dengan skizofrenia pada penelitian ini dapat terlihat pada hasil analisa statistik penelitian yang didapatkan yakni $p$-value $=0,000$, dimana nilai ini lebih kecil dari $\alpha=0,05$. Hal ini berarti bahwa terdapat perbedaan skor kecemasan yang signifikan atau bermakna sebelum dan sesudah dilakukannya terapi FPE. Hasil ini menunjukkan terapi FPE efektif dalam menurunkan kecemasan.

Hasil penelitian ini sesuai dengan penelitian Octryna (2013) yang melakukan penelitian pengaruh ACT (Acceptance and Comitment Therapy) dan psikoedukasi keluarga terhadap depresi dan ansietas pada keluarga yang merawat pasien HIVIAIDS. Penelitian ini menunjukkan terjadi penurunan ansietas dari berat menjadi ringan.

Penelitian ini juga didukung oleh hasil penelitian Rohmi (2015) tentang ansietas pada keluarga yang merawat pasien TB paru. Hasil penelitian menunjukkan penurunan ansietas setelah diberikan psikoedukasi. Ansietas dengan tingkat sedang menurun menjadi ansietas ringan.

Masalah psikososial yang paling sering terjadi pada keluarga yang merawat anggota keluarga dengan skizofrenia adalah kecemasan (Cabral, L., Duartea, J., Ferreiraa, M., Santos, C., 2014). Tingkat kecemasan bervariasi mulai dari cemas ringan sampai cemas berat tergantung dari mekanismen koping yang dimiliki oleh keluarga tersebut dan kekuatan faktorfaktor yang mempengaruhi terjadinya kecemasan itu sendiri. Hal ini sesuaii dengan teori bahwa kecemasan merupakan pengalaman individu yang bersifat subyektif yang sering bermanifestasi sebagai perilaku yang disfungsional yang diartikan sebagai perasaan "kesulitan" dan kesusahan terhadap kejadian yang tidak diketahui 
dengan pasti (Varcarolis, 2008). Hasil penelitian memperlihatkan terjadi penurunan kecemasan. Menurut peneliti, hal tersebut terjadi disebabkan oleh bertambahnya informasi yang didapat oleh keluarga. FPE memberikan informasi kepada keluarga tidak hanya terkait penyakit tetapi memberikan kesempatan kepada keluarga untuk mengungkapkan perasaan dan berbagi pengalaman, informasi serta pengelolaan kecemasan yang dialami oleh keluarga selama merawat penderita skizofrenia. Hal ini sesuai dengan pernyataan Chien (2008) yang mengatakan bahwa FPE mampu mengembangkan pengetahuan keluarga yang berpartisipasi dalam perawatan klien skizofrenia serta mampu mengelola efek psikosial seperti kecemasan yang dialami sebagai akibat dari merawat penderita skizofrenia (Jewell et al, 2009).

Pengelolaan kecemasan dilaksanakan pada sesi 3 FPE. Keluarga diberi informasi tentang pengertian, tanda dan gejala serta cara mengatasi kecemasan, kemudian keluarga diajak untuk berdiskusi dan mengungkapkan perasaan terkait penyebab kecemasan yang dialami oleh keluarga dalam merawat penderita skizofrenia. Keluarga dan terapis akan mendiskusikan cara mengatasi kecemasan yang tepat untuk keluarga. Beberapa responden menyatakan mengalami penurunan kecemasan setelah diberikan psikoedukasi selama 4 minggu.

\section{Perbedaan Beban Keluarga Dalam Merawat Anggota keluarga dengan Skizofrenia Sebelum dan Sesudah Terapi FPE}

Hasil penelitian memperlihatkan skor beban pada kelompok perlakuan mengalami penurunan. Penurunan tersebut terlihat dari hasil $U j \mathrm{ji} T$ Berpasangan antara beban sebelum dan sesudah terapi FPE, dengan nilai $p=0,000$. Hasil ini menunjukkan terapi FPE berpengaruh dalam menurunkan beban keluarga.

Beban keluarga merupakan tingkat distress keluarga karena adanya efek dari keberadaan anggota keluarga yang sakit (Pityasari, 2009). Beban keluarga dapat berhubungan dengan kekhawatiran tentang masa depan (Stuart, 2016). Caregiver atau keluarga yang merawat penderita skizofrenia memiliki kekhawatiran terhadap masa depan penderita. Persepsi terkait sakit yang tidak kunjung sembuh, yang membutuhkan perawatan rutin dan berkelanjutan dan adanya stigma masyarakat menjadi beban tersendiri bagi keluarga. Hal yang paling membebani adalah dampak terhadap kenyamanan mereka sehari-hari (Fitrikasari, A., Kadarman, A., Woroasih, S., Sarjana, W., 2012).

Pada sesi 4 keluarga mendapat informasi terkait beban dan cara mengatasi beban. Kemudian keluarga bersama terapis selanjutnya melakukan diskusi terkait beban yang ada dalam keluarga ataupun caregiver sendiri selama merawat penderita skizofrenia. Diakhir pertemuan pada sesi 4, keluarga dan terapis menyepakati bersama cara mengatasi beban dan peran masing-masing.

Hasil penelitian ini sesuai dengan penelitian yang dilakukan oleh Fallahi et al, (2014) tentang efek dari psikoedukasi terhadap beban keluarga terutama caregiver pasien skizofrenia di Iran. Penelitian dilakukan pada 71 caregiver yang dibagi dalam 35 kelompok kontrol dan 36 kelompok perlakuan. Setelah dilakukan perlakuan selama 1 bulan didapatkan hasil $p<0,01$. Hal ini menunjukkan penurunan beban keluarga yang signifikan setelah dilakukan psikoedukasi pada keluarga pasien skizofrenia di Iran.

Penelitian lain dilakukan oleh Pailli et al (2015) dan memperoleh hasil terkait efek grup pada keluarga pasien skizofrenia pada aspek kohesi, beban dan tanda gejala depresi keluarga. Hasil penelitian ini ada penurunan yang signifikan pada beban keluarga secara global dan beban keluarga obyektif. Sedangkan beban subyektif tidak mengalami penurunan.

Pendapat peneliti terkait hasil penelitian adalah psikoedukasi yang diberikan caregiver mampu menurunkan beban baik subyektif maupun obyektif. Beban subyektif yang dirasakan oleh caregiver seperti malu, stress dan frustasi mulai berkurang. Bahkan sekitar 7 dari 10 responden mengatakan bangga karena mampu merawat penderita skizofrenia. Sedangkan beban obyektif yang terkait dampak negatif terhadap kesehatan fisik anggota keluarga berkurang karena 
keluarga mampu memanajemen beban, hubungan anggota keluarga semakin baik dan adanya pembagian tugas untuk merawat penderita skizofrenia. kartu jaminan kesehatan serta kedatangan petugas puskesmas ke posyandu/ke rumah penderita mengurangi beban finansial.

\section{Perubahan Kecemasan Keluarga Dalam Merawat Anggota keluarga dengan Skizofrenia Sebelum dan Sesudah Pendidikan Kesehatan}

Hasil uji $T$ Berpasangan antara ansietas sebelum dan sesudah pendidikan kesehatan adalah $p=0,072(p>\alpha=0,05)$. Hal ini berarti bahwa tidak terdapat perbedaan skor kecemasan yang signifikan atau bermakna sebelum dan sesudah dilakukannya penyuluhan kesehatan. Hasil ini menunjukkan pendidikan kesehatan tidak efektif dalam menurunkan kecemasan keluarga merawat anggota keluarga dengan skizofrenia.

Pendidikan kesehatan pada hakekatnya adalah usaha penyampaian pesan kepada masyarakat, kelompok atau individu dengan harapan adanya peningkatan pengetahuan sehingga meningkatkan perilaku sehat yang lebih baik (Nootoatmojo, 2015). Pendidikan kesehatan yang diberikan kepada keluarga adalah tentang pengertian, tanda dan gejala, perawatan serta pengobatan penderita skizofrenia dengan menggunakan slide dan leaflet. Kurangnya informasi keluarga tentang skizofrenia dapat mengakibatkan kecemasan pada keluarga. Berdasarkan konsep tersebut maka peneliti memberikan penyuluhan dengan tujuan agar pengetahuan keluarga tentang skizofrenia meningkat sehingga terjadi penurunan kecemasan keluarga dalam merawat anggota keluarga dengan skizofrenia.

Namun pada penelitian ini tidak terjadi perubahan kecemasan yang bermakna secara statistik meskipun terdapat sedikit penurunan kecemasan. Peneliti berpendapat bahwa pendidikan kesehatan yang diberikan kepada keluarga belum mampu meningkatkan pengetahuan keluarga karena hanya diberikan sekali saja. Media yang digunakan saat dilakukan penyuluhan kesehatan adalah lembar balik dan leaflet, kemungkinan penyerapan informasi kurang optimal. Selain itu pada kelompok kontrol ini tidak diberikan teknik untuk mengontrol atau mengatasi kecemasan yang dialami keluarga. Pada dasarnya, pendidikan kesehatan sangat efektif terutama untuk meningkatkan kemampuan kognitif, namun untuk penurunan masalah psikososial yang melibatkan afektif seperti kecemasan dibutuhkan intevensi lanjutan yaitu FPE. Pengetahuan keluarga tentang skizofrenia dapat meningkat dengan baik namun untuk mengelola masalah-masalah yang berkaitan dengan perasaan memerlukan latihan, rutinitas dan waktu yang relatif lama. Hal ini sesuai dengan penelitian Gyamfi et al (2009) yang menyebutkan ada 3 faktor yang harus dilakukan pada proses pendidikan yaitu adopsi, implementasi dan maintenance/pemeliharaan. Pemeliharaan ini dapat dilakukan dengan latihan yang rutin agar menjadi suatu kebiasaan sehingga jika pendidikan kesehatan hanya dilakukan sesaat dan tidak dicontohkan cara untuk dilakukan manajemen kecemasan, maka keluarga akan tetap kesulitan mengatasi masalah-masalah psikososial dalam keluarga.

\section{Perubahan Beban Keluarga Dalam Merawat Anggota keluarga dengan Skizofrenia Sebelum dan Sesudah Pendidikan Kesehatan \\ Hasil penelitian memperlihatkan skor} beban keluarga pada kelompok kontrol mengalami penurunan. Penurunan tersebut terlihat dari hasil Uji T Berpasangan antara beban sebelum dan sesudah pendidikan kesehatan, dengan nilai $p=0,072$. Hal ini berarti bahwa tidak terdapat perbedaan skor beban yang signifikan atau bermakna sebelum dan sesudah dilakukan pendidikan kesehatan.

Kelompok kontrol yang diberikan pendidikan kesehatan tidak mampu menurunkan beban keluarga dalam merawat penderita skizofrenia. Notoatmodjo (2010) menyatakan bahwa pendidikan kesehatan adalah suatu proses dimana proses tersebut mempunyai masukan (input) dan keluaran (output). Di dalam suatu proses pendidikan kesehatan yang menuju tercapainya tujuan promosi, yakni perubahan perilaku oleh berbagi faktor. Faktor yang mempengaruhi suatu proses pendidikan disamping faktor masukannya 
sendiri juga faktor metode, faktor materi atau pesannya, pendidik atau petugas yang melakukannya dan alat-alat bantu atau media yang digunakan untuk menyampaikan pesan. Agar dicapai suatu hasil yang optimal maka faktor-faktor tersebut harus bekerja sama secara optimal. Hal ini berarti bahwa untuk masukan tertentu harus menggunakan cara tertentu dengan materi dan alat bantu yang sesuai.

Pada penelitian ini, pendidikan kesehatan yang diberikan menggunakan lembar balik dan leaflet. Menurut peneliti, media yang digunakan kurang efektif. Hal ini sesuai dengan penelitian Melina, F; Sobiyanto, AA; Wujoso, H. (2014) yang menemukan adanya perbedaan pengaruh media pembelajaran leaflet dan video terhadap keterampilan sadari.

\section{Perbedaan Kecemasan Keluarga Dalam Merawat Anggota Keluarga Dengan Skizofrenia Sesudah Intervensi Pada Kelompok Kontrol dan Perlakuan}

Berdasarkan hasil uji $\mathrm{T}$ tidak berpasangan didapatkan nilai $p=0,000$. Karena nilai $p<0,05$ maka dapat disimpulkan bahwa secara statistik terdapat perbedaan kecemasan yang bermakna antara kelompok perlakuan dengan kelompok kontrol setelah diberikan intervensi.

Pada sesi 3 psikoedukasi dilakukan intervensi untuk kecemasan. Peneliti menanyakan pada keluarga terkait kecemasan yang dialami keluarga. Lalu peneliti menjelaskan tentang kecemasan serta cara mengelola kecemasan. Keluarga kemudian mengidentifikasi kembali tanda dan gejala kecemasan yang dialami serta mendemonstrasikan cara mengendalikan kecemasan. Beberapa responden menyatakan mengalami penurunan kecemasan setelah diberikan psikoedukasi selama 4 minggu.

Tujuan utama dari terapi FPE adalah saling bertukar informasi tentang perawatan kesehatan mental akibat penyakit yang dialami, membantu anggota keluarga mengerti tentang penyakit anggota keluarganya seperti gejala, pengobatan yang dibutuhkan untuk menurunkan gejala dan lainnya (Varcarolis, 2006). Pelaksanaan psikoedukasi yang dilakukan dengan tepat dan dengan jangka waktu yang tidak terlalu lama serta evaluasi yang baik pada setiap sesinya akan meningkatkan kondisi sosial setiap anggota keluarga, karena jika caregiver merasakan cemas berlebih dampak negatif juga akan dirasakan oleh kelaurga.

Hal ini dikuatkan oleh penelitian Allen, et al (2007) yang menyatakan bahwa pengalaman caregiver melalui keluarga memegang peranan penting terhadap kesehatan psikososial, hubungan keluarga dan pola asuh dalam keluarga tersebut, dimana rata-rata caregiver juga mengalami hal yang sama. Beberapa responden menyatakan sering mengalami kecemasan yang dirasakan mengganggu dan mempengaruhi aktifitas sehari-hari. Responden menyadari hal tersebut adalah suatu masalah dan mereka ingin keluar dari masalah tersebut, dengan diberikan terapi FPE kecemasan yang dialami berangsurangsur berkurang pada kelompok perlakuan.

Sedangkan responden pada kelompok kontrol menyatakan pemahaman tentang skizofrenia sedikit meningkat tetapi dalam hal kecemasan masih sering merasakan cemas dan tidak mengerti cara menurunkan kecemasan. Hal ini menunjukkan bahwa ada perbedaan yang berarti antara kelompok perlakuan dan kelompok kontrol yang mengindikasikan adanya pengaruh psikoedukasi keluarga terhadap penurunan kecemasan.

\section{Perbedaan Beban Keluarga Dalam Merawat Anggota Keluarga Dengan Skizofrenia Sesudah Diberikan Intervensi Pada Kelompok Kontrol dan Perlakuan}

Hasil penelitian menunjukkan bahwa nilai rata-rata beban keluarga yang merawat anggota keluarga dengan skizofrenia pada kelompok perlakuan setelah pemberian terapi FPE sebesar 41,72 sedangkan pada kelompok kontrol sebesar 45,22. Melihat hasil analisis tersebut berarti bahwa nilai rata-rata beban keluarga yang merawat anggota keluarga dengan skizofrenia pada kelompok perlakuan setelah pemberian terapi FPE lebih tinggi sebesar 3,50 poin dibandingkan pada kelompok kontrol.

Hasil penelitian ini sesuai dengan literature yang menyatakan bahwa pada prinsipnya terapi FPE membantu anggota 
keluarga dalam meningkatkan pengetahuan tentang penyakit melalui pemberian informasi dan pendidikan yang dapat mendukung pengobatan dan rehabilitasi pasien (Carson, 2000). Pertemuan dalam pelaksanaan terapi FPE memberikan kesan saling membagikan perasaan yang dirasakan.

\section{KESIMPULAN}

1. Ada perbedaan kecemasan keluarga dalam merawat anggota keluarga dengan skizofrenia sebelum dan sesudah pemberian terapi FPE.

2. Ada perbedaan beban keluarga dalam merawat anggota keluarga dengan skizofrenia sebelum dan sesudah pemberian terapi FPE.

3. Tidak terdapat perbedaan kecemasan keluarga dalam merawat anggota keluarga dengan skizofrenia sebelum dan sesudah penyuluhan kesehatan.

4. Tidak terdapat perbedaan beban keluarga dalam merawat anggota keluarga dengan skizofrenia sebelum

\section{DAFTAR PUSTAKA}

Allen et al. (2007). Predictors, costs and characteristics of out of are placement for people with intelelectual disability and challenging behavior. Journal of Intellectual Disabillity Research, (51)6, 409-416.

American Psychiatric Association. (2013). Diagnostic and Statistical Manual of Mental Disorders. 5th ed, text rev. Washington, DC: American Psychiatric Association.

Cabral, L., Duarte, J., Ferreira, M., Santos, C., (2014). Anxiety, stress and depression in family caregivers of the mentally ill. Aten Primaria, 46, 176-179.

Carson, V.B. (2000). Mental health nursing: the nurse-patient journey. $2^{\text {nd }}$ ed. Philadelphia: W.B. Saunders Company.

Cerino, S., Cinelly, F., Chiarotti, F. \& Seripa, S. (2011). Non conventional psychiatric rehabilitation in schizophrenia using therapeutic riding: The FISE multicentre Pindar dan sesudah penyuluhan kesehatan.

5. Terdapat perbedaan kecemasan keluarga dalam merawat anggota keluarga dengan skizofrenia pada kelompok kontrol dan perlakuan.

6. Terdapat perbedaan beban keluarga dalam merawat anggota keluarga dengan skizofrenia pada kelompok kontrol dan perlakuan.

\section{SARAN}

Pelayanan kesehatan di tingkat primer, tidak hanya berfokus pada pelayanan fisik tetapi juga terhadap masalah psikososial yang muncul akibat skizofrenia maupun oleh masalah fisik itu sendiri. Perlu diprogramkan dan dilaksanakan jadwal kegiatan pendidikan kesehatan bagi keluarga yang selama ini tidak ada, difokuskan pada kegiatan promotif, preventif dan kuratif. Mengaplikasikan terapi FPE sebagai terapi lanjut untuk menurunkan kecemasan dan beban keluarga.

project. ANIMA-Asisted Interventions In Mental Health. 47(4): 409-414.

Chan, S. W., Yip, B., Tso, S., Cheng, B., \& Tam, W. (2009). Evaluation of a psychoeducation program for Chinese clients with schizophrenia and their family caregivers. Patient Education and Counseling, 75, 6776.

Chien, W. T. (2008). Effectiveness of psychoeducation and mutual support group program for family caregivers of Chinese people with schizophrenia. The Open Nursing Journal, 2, 28-39.

Devaramane, V. (2011). The effect of a brief family intervention on primary carer's

fungtioning and their schizophrenic relatives levels of psychopatology in India. Asian journal of psychiatry. 4 (3): 183-187.

Fitrikasari, A., Kadarman, A., Woroasih, S., Sarjana, W., (2012). Gambaran beban caregiver penderita skizofrenia di Poliklinik rawat Jalan 
Rumah Sakit Jiwa Amino Gondohutomo Semarang. Medica Hospitalia, Vol. 1(2), 118-122.

Fleming, D. A., Sheppard, V. B., Mangan, P. A., Taylor, K. L., Tallarico, M., Adams, I., \& Ingham, J. (2006). Caregiving at the end of life: Perceptions of health care quality and quality of life among patients and caregivers. Journal of Pain and Symptom Management, 31, 407420.

Friedman. (2010). Keperawatan keluarga teori dan praktek. $5^{\text {th }}$ ed. Jakarta : EGC.

Gonzales, C, et al. (2010). Effect of Family Psychoeducation on Expressed Emotion and Burden of Care in FirstEpisode Pshycosis : A Prospective Observasional Study. The Spanish Journal of Psychology. Vol. 13.

Gyamfi et al. (2009). Family education and support service in system of care. Journal of Behavior Disordes. 20(10).

Hawari, D. (2009). Pendekatan holistik pada gangguan jiwa skizofrenia. Jakarta : FK-UI.

Ingkiriwang, E. (2010). Penggunaan Metode Dua Menit dalam Menentukan Prevalensi Gangguan Jiwa di Pelayanan Primer. 60(10):449.

Jewell, T. C., Downing, D., \& McFarlane, W. R. (2009). Partnering with families: Multiple family group psychoeducation for schizophrenia. Journal of Clinical Psychology, 65(8), 868-878.

Johnson, D.L. (2012). Family education or behavioral family psychoeducation: making a choice. British Journal of Psychiatry. 165: 239-247.

Maldonado, J.G., Uri'zar, A.C. (2007). Effectiveness of a psychoeducational intervention for reducing burden in latin american families of patients with schizophrenia. Quality of Life Research. 16:739-747 DOI 10.1007/s11136-007-9173-9.

Melina, F., Soebiyanto, AA., Wujoso, H. (2014). Perbedaan media pembelajaran (Leaflet dan Video) terhadap keterampilan Sadari ditinjau dari motivasi. Jurnal
Kesehatan Samodra IImu, 05(2) 117-125.

Mitsonis, C., Voussoura, E., Dimopoulos, N., Psarra, V., Kararizou, E., Latzouraki, E., ... Katsanou, M. -N. (2012). Factors associated with caregiver psychological distress in chronic schizophrenia. Social Psychiatry and Psychiatric Epidemiology, 47, 331-337.

Mizuno, E., Iwasaki, M., Sakai, I., Kamizawa, N. (2012). Sense of coherence and quality of life in family caregivers of persons with schizophrenia living in the community. Archives of Psychiatric Nursing, Vol. 26, No. 4 (August),: pp 295-306.

National Institute for Health and Clinical Excellence (NICE). (2009). Schizophrenia: Core interventions in the treatment and management of schizophrenia in primary and secondary care, NCG 82. London: NICE. Available in www.nice.org.uk/nicemedia/live/117 86/43608/43608.pdf.

Notoatmodjo, S. (2007). Promosi kesehatan dan ilmu perilaku kesehatan. Jakarta: Rineka Cipta.

Octryna, Silitonga R. (2013). Pengaruh acceptance and commitment therapy dan family psychoeducation terhadap kemampuan menerima dan berkomitmen dalam mengatasi kondisi depresi dan ansietas pasien HIVIAIDS. Fakultas Keperawatan; Universitas Indonesia. Jakarta.

Pahlavanzadeh, S., Navidian, A. \& Yatdani, M. (2010). The effect of psychoeducation on depression, anxiety and stress in family caregivers of patients with mental disorders. Behbood journal. 14(3): 228-236.

Palli, A., Kontoangelos, K., Richardson, C., \& Economou, M.P. (2015). Effects of group psychoeducational intervention for family members of people with schizophrenia spectrum disorders: results on family cohesion, caregiver burden, and caregiver depressive symptoms. International Journal of Mental Health, 44(4), 277-289.

Rodrigo, C., Fernando, T., Rajapakse, S., De Silva, V., \& Hanwella, R. (2013). 
Caregiver strain and symptoms of depression among principal caregivers of patients with schizophrenia and bipolar affective disorder in Sri Lanka. International Journal of Mental Health Systems, 7, 2-7.

Rohmi, Faizatur. (2015). Pengaruh psikoedukasi keluarga terhadap tingkat kecemasan dan kemampuan keluarga dalam merawat penderita TB di Puskesmas sumbermanjing Wetan Kecamatan Sumbermanjing, Kabupaten Malang. Fakultas Kedokteran; Universitas Brawijaya, Malang.

Shah, S. T. H., Sultan, S. M., Faisal, M., \& Irfan, M. (2013). Psychological distress among caregivers of patients with schizophrenia. Journal of Ayub Medical College, Abbottabad: JAMC, 25, 27-30.
Stuart, G.W. \& Laraia, M.T. (2008). Principles and practice of psychiatric nursing. $8^{\text {th }}$ ed. St. Louis : Mosby Yaer B.

Stuart, G.W. (2013). Principles and practice of pschyatric nursing-10th ed. United States of Amerika: Mosby Elsevier.

Varcarolis, E.M., Carson, V.B. \& Shoemaker, N.C. (2008). Foundations of Psychiatric Mental Health Nursing, 5th Edition, Saunders Elsevier, USA..

Videbeck, S. L,. (2008). Buku Ajar Keperawatan Jiwa. Jakarta: EGC. 